itself stimulated, ascending tracts carry to the hypothalamus the effects of this excitation of the taste organs, and through it stir up even more potent effects in the digestive and other visceral systems.

It is something more than a mere coincidence that the pituitary body is developed from a combination of buccal epithelium and hypothalemus, and is an organ which excites (no doubt by very different means) profound effects in the visceral systems, in some respects analogous to that ubtained by the neural bucco-hypothalamic connexion.

Thus the hypothalamus represents the mechanism whereby the instruments concerned with the phenomena of consciousness can influence the visceral functions of the body, and express those manifold emotional effects which play so obtrusive a part in many experiences that are strongly charged with affective tone.

In the first lecture emphasis was laid upon the ana. tomical facts $(a)$ that the cerebral hemisphere was derived from and built upon what in the primitive vertebrate was simply the receptive instrument for smell impressions; and $(b)$ that the olfactory tracts, unlike all the other sensory patlss, lead directly to the cerebral cortex without the intermediation of the thalamus. The primitive hemisphere, therefore, must have been the instrument whereby the affective aspect of smell was appreciated-that is, it performed the functions with which the thaiamus is concerned for the other senses.

Guided by the sense of smell, the bohaviour of the primitive vertebrate is brought under the influence of o.ther "distanee-receptors," which secondarily acquire an affective significance or meaning by being brought into in timate relationship with the dominant sense. Specializa. tions of structure and function then develop by the cultivation of these other senses, often at the expense of the sense of smell, and animals like the teleostean fishes are evolved which are guided mainly by vision. This deter, mines a high development of the mid-brain and a retrogression of the cerebral hemisphere. Incidentally such ereatures lose the possibility of further advancement in the direction of the higher vertebrates, not merely because they have become specialists, but also because the adapta. bility of the cerebral hemisphere upon which real progress depends has been sacrificed in the acquisition of visual efficiency.

After discussing other variations that occur in fishes, the momentous changes effected in the brain by the adoption of life upon land and the emergence of the Tetrapoda were next considered.

The new mode of life demanded not only the develop. ment of entirely new modes of locomotion, but also a transformation of the distance receptors of the hind-brain, as well as the organs of smell.

For the organ that was evolved to detect slight move. ments in the water became the organ of hearing, and the olfactory mucosa, which was specialized to respond to very delicate forms of chemical stimulation, now became much more highly sensitive and adapted to appreciate the more subtle effects of minute air-borne particles of odoriferous substances.

The heightened powers of smell, the new powers of hearing, and the necessity for acquiring new methods of lacomotion, provided a powerful stimulus to the cerebral hemisphere; and there are reasons for supposing that the earliest Tetrapoda were provided with a brain with a welldeveloped cerebral cortex. But their surviving amphibian descendants only in part emancipated themselves from the aquatic mode of life, and were satisfied with slow-going clumsy movements of a simple character. As the result their cerebral cortex underwent a process of retrogression, and the amphibia dropped out of the race for vertebrate supremacy.

But one group of proto-amphibians was more progressive. They acquired the power of more rapid movement and of more saried response to the influence of their environment. The sensitivity of touch, smell, vision, and hearing became heightened and the influence of these senses so intimately integrated by revolutionary changes in the cerebral hemisphere as to make possible a much more complex and intelligent behaviour. The increasing significance of vision, hearing, and touch, foumd expression in the sudden growth of the thelamus and the development of larger tracts of fibres ascending from the thalamic nuclei into the lateral edge of the pallium, which then suddenly expanded and bulged into the ventricle. The great mass of low.grade pallium, which may be called "hypopallium," thus formed represents the first relatively independent representation in the cortex of the senses of vision, hearing, and touci at first chiefly of the trigeminal nerve. Then for the first time the cerebral cortex became an instrument whereby these senses played a combined part in controlling be haviour and added their quota to the discriminative side of the animal's consciousness. The reptile thus came to acquire the power of learning by experience from other senses than smell and of correlating the information acquired by touch, vision, and hearing, to perform acts of discrimination in which these several senses took a definite part.

But this hypopallium was an imperfect instrument; and when it became superseded by the development of the higher mechanism of the neopallium, it (the hypopallium) became converted into [the greater part of] the nucleus caudatus, the putamen and the claustrum.

\section{RECONSTRUCTION IN MEDICAL EDUCATION.}

Being the Presidential AdDress delivered to the Metropolitain Counties Branch of the British Medical association. BY

Lievt.-Colonel W. McadaM ECCLES, M.S., M.B., F.R.C.S., R.A.M.C.(T.F`),

SURGEON TO ST. BARTHOLOMEW'Y HOSPITAL; PRESIDENT

WhEn Peter, in Joan and Peter, was asked by his guardian to plan his own school, Peter considered and then said "I'd like lessons about the insides of animals, and about the people in foreign countries-and how engines workand all that sort of thing."

This was revolutionary, and, according to the recoguized educational authorities, could not be permitted under any circumstances; hence Sydenhan's visit to the appointed source of knowledge proved a dismal fiasco, and lie wiss faced with the task of finding a sphere within which "reconstructed" education was really existent. He failecl to find it, and by just such a degree Peter failed to secure what such an education would have provided. He was not much the worse for it, but he might have been so much the better had he had it.

The medical schools of Great Britain and Ireland have always had before them one principal object-the trainin. of good general practitioners of medicine-and they have succeeded, for there is no other country in the world where such exce!lent men and women doctors can be found.

But medicine, surgery, and the allied subjects are always advancing, and the capacity of the human brain finds it difficult to keep pace with the advancement. For this, if for no ather reason, reconstruction in medical education is called for.

Let me instance what I mean. When I was a student, not so very many years ago, all the medical out-patient work was done in a poor ill.equipped set of rooms, hidden away in a remote and rather dark corner of the hospital. Now there is a whole suite of rooms, well lit, well equipped, and used solely for its purpose. All the operative work on the surgical side was performed in a single operation theatre not used every day of the week. Now there are thirteen operation rooms of various sizes and for different departments. The entire accommodation for pathology was a poorly furnished room off the physiological department, enough perhaps, as only about half a dozen varieties of bacteria were known. Now the sections of pathology, general, histological, bacteriological, chemical, and research, are loused in a building which cost $£ 30,000$; and so it is with every other department.

In the face of these facts how is the student to be taught so that what he learns shall be adequate and sound? This is really the problem of reconstruction in medical educa. tion. The old was good, and the good that was in it must not be lost. The new is better, but its very vastness implies a danger. The preliminary and intermediate sub. jects, all of which are large sciences in themselves, have the possibility that they may be taught from an academic rather than from a practical point of view. Physios, chemistry, and biology - the foundations of a medical 
education-must be taught, sometimes sufficiently learnt, at sclool, but they ought to be taught in their bearing upon the practice of medicine, hence perhaps the value of their being so taught at a medical school. At the public school, even with a modern side, the education in these sciences is apt to be sketchy and subsidiary, and frequently quite apart from their after-relation to medicine. At a university or medical school or science department they may be too elaborately expanded. Physiology and anatomy, the ground floor of medical knowledge, huge subjects and needing to be kept within bounds, must receive their proper and proportionate place. Physiology is the more difficult to handle. It is less concrete, constantly changing, somewhat elusive and uncertain, but the knowledge of all natural and normal functions is essential for a proper estimation of the abnormal as seen in disease. Anatomy, with its solid parts and form, is increasingly important with the expansion of operative procedure. The pure physiologist and the pure anatomist teaches without daily contact with the clinical, and are apt to wander from the practical application of their facts to the everyday practice of medicine and surgery, and in this lurks further danger. To a large extent this can be avoided by closer interrelations between these teachers and the clinical side. It is helpful to all concerned when the physiologist and the anatomist accompany the physician into the ward or outpatient room and discuss, in the hearing of the students, the bearing of their subjects upon a somewhat obscure nervous lesion. In "recoustructive" plans this "team" work between the intermediate (and even the preliminary) subjects should bear an important part.

In the advanced subjects-medicine, surgery, obstetrics, gynaecology, ophthalmology, and all the allied departments - the enormons strides made in methods of diagnosis and treatment has made the task of the teacher more and more intricate, and the burden on the student of absorbing and retaining what he is taught more and more difficult. Whatever else happens, nothing must occur which shall imperil the splendid bedside and other practical teaching for which British medical education is so famous. It forms the superstructure of knowledge for subsequent practice. It brings the student into personal and close contact with the patient. It develops all that tactus eruditus and all that savoir faire which should enter so largely into the character and actions of the practitiones. Go where you will, and you cannot find better general practitioners than in our isles and in our empire. But this fact must not blind our eyes to the vision of even better men and women-better equipped, better paid, and better rewarded in the future than in the past.

For all this reconstruction in medical education is surely needed; not revolution but reconstruction, not throwing away the good in the old, but grafting on the better in the recent.

Sir George Newman, to whose recent Notes* must be ascribed a great up-lift for medical education, has put the finger on the spot when he writes: "There is too little medical teaching of university standard, especially in the tinal or clinical subjects."

There can be no doubt that it is due primarily to the fact that the clinical teachers when their experience is ripe have not the time, and often have not the inclination, for such teaching. The more the pity, but there is the bald fact. The primary question, therefore, would seem to be, How can this defect be over'come?

A possible solution, and one which will soon be put to the test, is the foundation of units of a professional type in the three chief branches of medicine-surgery and obstetrics and gynaecology. Men (or women) in the prime of 1 ife, of proved teaching ability, of ripe experience, with the love of and powers for inculcating a scientific spirit, appointed as whole-time professors or directors of clinic. Associated with them, assistant professors in training for professorships in their own school or elsewhere, and other well-paid assistants, clinical and pathological-the whole unit working together as a team.

They would undertake bedside teaching, possibly upon a series of cases-say of types of anaemia-gathered together in their wards at that time for special research work; outpatient teaching, again perhaps on a group of similar cases,

* Some Notes on Medical Education in England. H.M. Stationery Ofice, 1918, price 9d. See Sir Clifford Allbutt's review in the JoCrsaL of August 3rd, 1918, p. Sil say types of hernia; super-clinical lectures, thoroughly worked up, with cases, skiagrams, drawings, lantern slides, and even cinema films; and co-ordinated, physiological, anatomical, and pathological teaching. It is hoped that every student will be brought in contact with the professorial unit during some part of his clinical education. Whilst the personnel of the professorial unit are engaged in this teaching of a university character, the otlier clinical units will continue their sound and essential teaching both in-patient and out-patient, and will have associated with them students of all grades. By this means proper vise will be made of the large amount of clinical material tliat finds its way to a hospital with an attached school.

Such is the vista; much may come of its accomplish. ment. There are difficulties. The type of men is rarte, adequate noney is not readily forthcoming, organization is none too easy; but difficulties are there to be overcome, and with perseverance they will be. It is particularly :desirable that what we can recognize as bad, or at least poor, in the Continental type of clinical professor shonld be excluded in our reconstruction, but it is equally neces. sary that all that is good should be included. The thoroughness, the painstaking, the science of many can be taken, but the inhumaneness, the machine-likeness, and the want of imagination of some can be avoided.

With the end of the war the medical schools are being filled with eager students, many of whom have learnt a wider and finer outlook of life and its responsibilities, and it is only right that they should be provided with: an education which will fit them for their life's work, and will give them such a grip of things that they will be a credit to their teachers and become a power in the land.

\section{ftlentaranda:}

\section{MEIICAL, SURGICAL, OBS'TETRICAL.}

\section{ACRIFLAVINE IN THE TREATMENT OH} GONORRHOEA.

Is a memorandum in your issue of June 7 th Captain Armstrong cites his experience with acriflavine, in contradistinction to that of Davis and Harrell, as evidence of the divergent views of different observers. May I offer a few suggestions which may enable any who have met with similar difficulties to approximate the clinical results to the laboratory results which are acknowledged?

One must be as confident as it is possible to be thathite infection is limited to the anterior urethra before adoptimg the syringe method of treatment. The main point in this connexion is the number of days since the appearance of the discharge; there must be no increased frequency tof micturition, and, of course, neither pus nor blood in the second urine glass. But in spite of careful selection, there will be a considerable percentage of error owing to carses coining under observation during the incubation period: of posterior urethritis. For this and other reasons I prefe as a routine treatment the lavation method described in my paper published in this Joursal on May 10th.

Acriflavine solution 1 in 1,000 may be irritating to the urethra, if used frequently and freely, or if unfiltered. When using the syringe method I prescribe a strength of 1 in 500 acriflavine in 1.6 per cent. sodium chloride solution, which is filtered by the dispenser, and in use is diluted with an equal quantity of warm water. The directions are that the syringe is to be used three times a day, and once in the night if occasion serves; the urethra is to be gently filled three times and the solution retained for one minute on each occasion. There is, however, no reason why a weaker solution (say 1 in 2,000) should not be used in a specially sensitive urethra; irritation must never, be excited. For lavation 1 in 4,000 should not be exceeded.

The absence of gonococci at the end of three 'teelss' treatment in 17 of the 23 cases quoted is so far satisfactory. The presence of pus cells and mucus was to be expected in the irritated condition of the urethras which is described. The six cases in which gonococci persisted called ifor further examination and a fuller diagnosis. There may have been posterior urethritis, a minute cystic glamd oozing at intervals, or a long infected duct; any of these call for special treatment. 